\title{
LAS OBRAS HUÉRFANAS: \\ PRESUPUESTOS TEÓRICO-JURÍDICOS PARA \\ SU EFECTIVA PROTECCIÓN EN CUBA ANTE \\ EL ACTUAR DE BIBLIOTECAS PÚBLICAS*
}

\author{
ELIANYS DIEGO PUENTES** \\ ANA MARÍA PEREDA MIRABAL ${ }^{* * *}$
}

\section{RESUMEN}

En Cuba no existe referencia en la Ley de Derecho de Autor a la protección de las obras huérfanas, y en consecuencia de sus creadores, aun cuando sí encuentra un reconocimiento expreso el límite a favor de bibliotecas. Ante la necesidad de que las bibliotecas públicas, en su actuar diario, puedan hacer uso de las obras huérfanas, sin que ello constituya una violación de las facultades autorales de dichos creadores, la presente investigación fundamenta los presupuestos teórico-jurídicos que deben amparar la protección en Cuba de obras huérfanas para evitar situaciones de conflicto entre la actividad que realizan las bibliotecas públicas y la protección de los derechos de sus autores.

Palabras clave: obras huérfanas, bibliotecas públicas, límites al derecho de autor.

\footnotetext{
* Licenciada en Derecho por la Universidad de Pinar del Río. Correo electrónico: elianisdiegopuentes@gmail.com. Pinar del Río (La Habana, Cuba). Fecha de recepción: 1. de marzo de 2020. Fecha de aceptación: 5 de abril de 2020. Para citar el artículo: Diego Puentes, Elianys y Pereda Mirabal, Ana María. Las obras huérfanas: presupuestos teórico-jurídicos para su efectiva protección en Cuba ante el actuar de bibliotecas públicas. Revista La Propiedad Inmaterial n. ${ }^{\circ}$ 29, Universidad Externado de Colombia, enero-junio, 2020, pp. 5-23. Dor: https://doi.org/10.18601/16571959.n29.01.

** Licenciada en Derecho. Especialista en Organización y Gestión del Estado. Máster en Derecho Civil. Profesora auxiliar de Derecho de Autor y Derecho Civil, Parte General en la Universidad de Pinar del Río "Hermanos Saíz Montes de Oca". Notaria con protocolo docente en la provincia de Pinar del Río (La Habana, Cuba). Correo electrónico: anamariapereda5@ gmail.com.
} 
THE ORPHAN PROJECTS: THEORETICAL-LEGAL BUDGETS FOR THEIR EFFECTIVE PROTECTION IN CUBA BEFORE ACTING IN PUBLIC LIBRARIES

\section{ABSTRACT}

In Cuba there is no reference in our Copyright Law to the protection of orphan works, and consequently of their creators, even if the limit in favor of libraries finds express recognition. Given the need of public libraries in their daily actions to make use of orphan works, without constituting a violation of authors rights, this research sets up bases for theoretical-juridical assumptions that must cover the protection in Cuba of orphan works in order to avoid situations of conflict between public libraries' activities of public libraries and the protection of authors' rights.

Keywords: orphan works, public libraries, limits on copyright.

\section{NOTAS INTRODUCTORIAS}

El derecho de autor surge con el propio acto de creación y concede al autor sobre su obra un conjunto de facultades morales y patrimoniales. Estas últimas, las patrimoniales, con posibilidad de ser transferidas y obtener en consecuencia una remuneración por ello, siempre y cuando se cuente con el consentimiento del autor. No obstante, existen supuestos en los que una obra protegida por el derecho de autor puede ser utilizada sin que ello implique previa autorización del autor o titular del derecho exclusivo. Estos usos libres pueden ser gratuitos o sujetos a remuneración, conformando lo que se denomina doctrinal y legalmente límites, limitaciones o excepciones al derecho de autor.

Se habla en consecuencia de un derecho subjetivo que tendrá, en sentido general, límites intrínsecos tales como: su propia definición legal, los principios de buena $\mathrm{fe}$, no abuso del derecho y los legítimos intereses de los autores. A la par de estos límites generales, el derecho de autor se encuentra limitado respecto a las facultades patrimoniales que posee. Límites que van encaminados a lograr un adecuado equilibrio entre el derecho de los creadores y el de los usuarios, estimulando de esta forma la labor creativa de los primeros y la satisfacción de las necesidades sociales de acceder al acervo cultural de los segundos.

Los límites y excepciones al derecho subjetivo del autor constituyen barreras en aras de garantizar el acceso del público a sus creaciones. Ellos propician que los creadores puedan acceder a otras obras en busca de inspiración, conocimiento y, a partir de ello, sigan creando sin que esto suponga necesariamente una remuneración para el autor o se requiera su consentimiento. Los límites están encaminados a garantizar el cumplimiento de la función social del derecho de autor, para fomentar de ese modo el acceso a la cultura y permitir que exista un justo equilibrio entre el 
autor que crea la obra y el público que necesita o desea disfrutar de sus creaciones sin restricción alguna.

Los límites y excepciones constituyen una parte importante del derecho de autor, teniendo en cuenta que estos definen sus contornos. Para la configuración normativa de los límites se tiene en cuenta el test o prueba de los tres pasos como norma habilitadora reconocida y establecida en el Convenio de Berna, en los Acuerdo sobre los Aspectos de los Derechos de Propiedad Intelectual relacionados con el Comercio (ADPIC) y los Tratados OMPI de 1996 (тоDA). De tal suerte, los límites se permiten cuando cumplen con cada una de las tres condiciones contenidas en la regla de los tres pasos de manera acumulativa, es decir, que se trate de casos especiales, que no atenten contra la normal explotación de la obra y no causen un perjuicio injustificado a los legítimos intereses de autores o titulares. La prueba de los tres pasos constituye un referente indispensable en materia de límites al derecho de autor, toda vez que permite que estos se erijan como punto de conexión que permita el acceso por instituciones, como las bibliotecas públicas, a todo tipo de obras, incluyendo las huérfanas.

Resulta pertinente destacar que las bibliotecas públicas constituyen importantes repositorios de información, que cumplen una destacada función social de acercamiento de la cultura y el saber a todas las personas en general. Precisamente por responder a un interés público, resultan beneficiarias de los límites que se establecen al derecho de autor. Las funciones habituales que realizan las bibliotecas públicas de colección, preservación y difusión de la información, implican normalmente la reproducción, distribución y comunicación pública de obras protegidas por el derecho de autor, por lo que, si esas actividades no estuviesen contempladas en tales límites, entrarían en conflicto con el derecho de los creadores de autorizar ese uso, ya sea de forma onerosa o gratuita.

Una vez incorporadas las obras a su acervo, las bibliotecas públicas ofrecen servicios de préstamos de ejemplares, consulta de obras en las propias instalaciones o mediante redes informáticas, el fotocopiado de materiales mediante máquinas instaladas al efecto in situ, la reproducción en micro-film de un documento en soporte papel, el préstamo interbibliotecario para satisfacer solicitudes de determinados usuarios, realizan copias de obras para sustituir ejemplares que se han deteriorado, perdido, o para cambiar formatos ya obsoletos ${ }^{1}$.

En los fondos bibliotecarios existen obras en dominio público y otras en dominio privado respecto a las cuales ya se ha obtenido la correspondiente autorización para hacer uso de ellas por medio de licencias concedidas por los titulares del derecho de autor, sea con remuneración o de forma gratuita ${ }^{2}$. A los efectos

1 Cfr. Valdés Díaz, C., "Los límites al derecho de autor a favor de bibliotecas en los países latinoamericanos. Especial referencia a Cuba”, en Serrano Fernández, M. (coord.), Estudio de los límites a los derechos de autor desde una perspectiva de derecho comparado. Reproducción, préstamo y comunicación pública en bibliotecas, museos, archivos y otras instituciones culturales, Ed. Reus, Madrid, 2017, pp. 150 y 151.

2 El autor goza, con exclusividad, del derecho de realizar por sí o de autorizar a terceros la explotación económica de la obra, por ello podrá transmitir su derecho a través de "cesión" la 
de la actividad de bibliotecas y los derechos de autor este tipo de obras no genera mayores complicaciones.

Sin embargo, la realidad indica que pueden existir obras que forman parte del acervo bibliotecario se encuentran en dominio privado, pero cuyos autores o titulares no pueden ser localizados. Doctrinalmente estas obras se conocen como "obras huérfanas". Serrano Fernández señala que son aquellas que están protegidas por los derechos de autor, cuyos autores no pueden ser identificados o localizados por quien quiere realizar actos de explotación que requieren el consentimiento del autor y han realizado una búsqueda diligente de dichos autores. Gran parte de las colecciones de las bibliotecas se conforman por este tipo de obras, siendo por ello imprescindible el establecimiento de límites que permitan que estas instituciones públicas realicen de forma lícita sus funciones sin entrar en conflicto con los creadores de las obras.

Esta necesidad se acentúa en momentos en que la digitalización del conocimiento se impone y cada vez más se demanda un acceso al conocimiento transfronterizo. En Cuba aunque existen normas que amparan el actuar de bibliotecas públicas ante la existencia de obras huérfanas, estas no se atemperan al entorno digital. Ante esta realidad la presente investigación fundamenta los presupuestos teórico-jurídicos que deben amparar la protección en Cuba de obras huérfanas para evitar situaciones de conflicto entre la actividad que realizan las bibliotecas públicas y la protección de los derechos de sus autores.

\section{LÍMITES ESTABLECIDOS AL DERECHO EXCLUSIVO}

\section{DE LOS AUTORES EN FAVOR DE LAS BIBLIOTECAS}

Los límites que benefician a las bibliotecas e instituciones similares les permiten llevar a cabo diversas actividades (facilitar a sus usuarios copias de un artículo o de

que puede ser: legal, o de pleno derecho por ministerio de la ley, o convencional, cuando el autor concierta un negocio jurídico con el utilizador de su obra y en consecuencia este último se convierte en titular derivado de las facultades que el autor ha consentido que sean ejercidas por él, produciéndose así la transmisión contractual de los derechos autorales.

La transmisión inter vivos, en principio, es una autorización de uso que otorga el titular del derecho de autor a otras personas para que estas puedan explotar su obra sin renunciar al derecho que se establezca, esta puede ser tanto por vía legal como voluntaria. La transmisión voluntaria o contractual de las facultades patrimoniales se produce por cesión, la que puede ser en no exclusiva o exclusiva. Cuando la cesión es no exclusiva no hay transmisión de facultades, solo una autorización de uso, conocida con las denominaciones de licencias o autorizaciones de uso. Mientras que cuando la cesión es exclusiva se produce una transferencia de facultades a favor del tercero para que utilice la obra de determinada forma. Se trata en un este último caso de un negocio jurídico de naturaleza contractual.

La transmisión inter vivos por cesión con transferencia de la titularidad del derecho de explotación ha sido rechazada, por ello la tendencia ha sido concebir el derecho patrimonial del autor como un derecho exclusivo a autorizar la utilización de la obra a través de licencias específicas, exclusivas o no exclusivas y reconocer la necesidad de que a través de normas imperativas las legislaciones incorporen una parte general relativa a los contratos de explotación de obras.

3 Serrano Fernández, M., "Los derechos de explotación de las obras huérfanas en el entorno digital: las dificultades de transposición de la Directiva 2012/28UE al ordenamiento jurídico español", en Serrano Gómez, E. (director), Anuario de Propiedad Intelectual 2013, Ed. Reus, Madrid, 2014, pp. 265 y 269. 
una pequeña porción de una obra, copiar obras completas por razones de archivo o preservación, prestar las obras a sus usuarios o a otras bibliotecas, etc.) sin la autorización del titular de los derechos y en algunos casos sin pagar ${ }^{4}$.

La digitalización de cualquier obra constituye un acto de reproducción. Esta técnica permite la descomposición de las obras en el lenguaje de series de ceros y unos (lenguaje binario). El resultado no es solo la obtención de una copia prácticamente idéntica de la obra sino que en otros supuestos permite que la obra digitalizada se mejore e incluso se conserve con un carácter casi perpetuo.

Cuando se emplean soportes electrónicos como el CD-ROM, CD-R, DVD-R, CD-RW, DVD-RW para divulgar fuera de línea la obra, es decir que la biblioteca los venda, alquile o preste, se configuran actos de distribución como facultad patrimonial de los creadores. Por otro lado, la transmisión digital que se hace a través de una red cerrada, como la intranet de una biblioteca, es un acto de comunicación pública en tanto pone a disposición de un número indeterminado de personas la obra.

Resulta evidente que para el desarrollo de sus funciones las bibliotecas necesitan amparar su actuar en una serie de límites. La configuración doctrinal y normativa de estos permite analizar su finalidad, cuáles son las entidades beneficiarias, el tipo de obras que afectan, los requisitos que deben configurarse para apreciarlos. Además de su desarrollo en entornos digitales y el empleo de soportes también digitales. Dentro de los derechos exclusivos que se limitan está el de reproducción 5 .

La Directiva 2001/29/CE en su artículo 2. ${ }^{\circ}$ alude a dicho término, refiriendo que se entiende por tal las copias directas o indirectas, provisionales o permanentes por cualquier medio y en cualquier forma, de la totalidad o parte de las obras o prestaciones protegidas ${ }^{6}$. Sin embargo, coincidiendo con el criterio de Carrancho

4 Fernández Molina, J. C., Preservación digital y derechos de autor: ¿un conflicto sin solución?, en v Congreso Nacional de Bibliotecas Públicas, Gijón, 2010. Disponible en: travesia. mcu.es. Consultado 1 de abril de 2017.

5 Cfr. Carrancho Herrero, $\mathrm{M}^{a}$ T., "El concepto de obra de plástica y la impresión en 3D”, en Espín Alba, I. (coord.), Propiedad intelectual en el siglo xxi: nuevos continentes y su incidencia en el Derecho de Autor, Ed. Reus, Madrid, 2014, p. 54. A tono con esta idea Lipszyc señala que el término divulgación tiene un significado más amplio que el de publicación. La facultad de divulgación englobará toda expresión de la obra que, con el consentimiento del autor, se haga accesible por primera vez al público en cualquier forma, mientras que por publicación, jurídicamente hablando, y con un sentido más restringido, se entiende la divulgación realizada con consentimiento del autor mediante la puesta a disposición del público de ejemplares de la obra, cualquiera que sea la forma de reproducción utilizada. Vid. Lipszyc, D., Derechos de Autor y derechos conexos, Unesco/Cerlalc/Zavalia, 1993, p. 161 y VALDÉs Díaz, C. C., Estudios cubanos sobre Derecho de Autor y derechos conexos, Ed. Organización Nacional de Bufetes Colectivos, La Habana, 2014, nota al pie número 14 de la p. 17 y p. 52

6 Cfr. artículo 2 de la Directiva 2001/29/CE del Parlamento Europeo y del Consejo del 22 de mayo de 2001 relativa a la armonización de determinados aspectos de los derechos de autor y derechos afines a los derechos de autor en la sociedad de la información. Disponible en https://eur-lex.europa.eu/LexUriServ/LexUriServ.do?uri=Celex:32001L0029:Es:HTML. Consultado el 25 de enero de 2019.

“Derecho de reproducción”: Los estados miembros establecerán el derecho exclusivo a autorizar o prohibir la reproducción directa o indirecta, provisional o permanente, por cualquier medio y en cualquier forma, de la totalidad o parte:

(a) a los autores, de sus obras;

(b) a los artistas, intérpretes o ejecutantes, de las fijaciones de sus actuaciones; 
Herrero, este concepto puede ser ampliado y entenderse que comprende por un lado la fijación mediante cambio de formato de una obra, pasando del formato analógico al digital a través del escaneado, por ejemplo, así como la obtención de copias, mediante fotocopiado, almacenamiento en memoria de ordenador, etcétera ${ }^{7}$.

Para que la reproducción sea válida y funja como límite a favor de las bibliotecas públicas, resulta necesario que el acto de reproducción cumpla una serie de requisitos, a saber, que las entidades que resultan beneficiarse de este límite sean de titularidad pública y con un carácter científico o cultural, o sea, que su creación se encuentre vinculada a la voluntad del Estado, como parte de una política pública de protección de los derechos de autor y en cumplimiento de la finalidad de este derecho subjetivo, la estimulación de la creación intelectual, la protección de la difusión del conocimiento y la promoción de la creación.

Se exige que el acto de reproducción tenga lugar con fines de conservación o investigación y sin que medie ánimo de lucro, así como la previa divulgación de la obra para hacer uso de ella, pues de otro modo se estaría afectando la facultad moral otorgada al autor de decidir la divulgación de su obra. En este sentido, piénsese que pueden existir en las bibliotecas obras depositadas mas no divulgadas, sería el caso de trabajos de tesis (de doctorado, máster, especialidad o licenciatura) ${ }^{8} \mathrm{o}$ epístolas inéditas (que por su originalidad pueden ser consideradas obras) donados por su destinatario a la institución mas no divulgadas ni publicadas por su autor? Asimismo vale la pena señalar que queda comprendido dentro de este límite el préstamo interbibliotecario, pues haciendo uso de las Tic, estos centros envían en dichos casos un escáner de la obra o en su caso una fotocopia, pues en la era digital resulta poco probable que se envíe el texto o material en formato original o el ejemplar único que posee la biblioteca.

(c) a los productores de fonogramas, de sus fonogramas;

(d) a los productores de las primeras fijaciones de películas, del original y las copias de sus películas;

(e) a los organismos de radiodifusión, de las fijaciones de sus emisiones, con independencia de que éstas se transmitan por procedimientos alámbricos o inalámbricos, inclusive por cable o satélite.

7 Vid. Carrancho Herrero, M. T., "Reproducción, préstamo y consulta en museos, archivos, bibliotecas y otras instituciones”, en De Román Pérez, R. (coord.), Propiedad Intelectual en las Universidades Públicas. Titularidad, gestión y transferencia, Ed. Comares, Granada, 2016, p. 148.

8 Ciertamente el tema sobre la consideración de obras divulgadas en el supuesto de las tesis (de doctorado, máster, especialidad o licenciatura) no está zanjado y existen criterios a favor y en contra. Para una reflexión más profunda, $c f r$. Alonso Arévalo, J., Garbajo Gascón, F., y Cordón García, J. A., "La propiedad intelectual y los derechos de autor en bibliotecas y centros de información: revistas digitales y acceso abierto", en Torres Ripa, J., y Gómez Hernández, J. A. (coords.), El copyright en cuestión: diálogo sobre propiedad intelectual, Bilbao, Deusto, 2011, pp. 143-168. Disponible en http://hdl.handle.net/10760/18064, consultado el 8 de octubre de 2019.

De Román Pérez, R. (coord.), Propiedad intelectual en la universidad pública. Titularidad, gestión y transferencia, Ed. Comares, Granada, 2016, p. 120-121, 369.

9 Sobre la improcedencia de realizar actos de divulgación de obras inéditas por bibliotecas ver Navarro Costa, R., "Algunas cuestiones sobre propiedad intelectual, bibliotecas e internet”, en Cuena Casas, M., Anguita Villanueva, L.A. y Ortega Doménech, J. (coord.), Estudios de Derecho Civil en homenaje al profesor Joaquín José Rams Albesa, Ed. Dykinson, Madrid, 2013, pp. 963-968. 
Con respecto a la remuneración, mucho se cuestiona desde el punto de vista doctrinal, teniendo en cuenta que no se reconoce una compensación a los autores por estas reproducciones, especialmente cuando se sabe que estas los pueden afectar, pues sin dudas el número de obras y reproducciones que de las ellas se hacen es mayor que los préstamos y consultas que se hacen en los centros especializados. Lo razonable sería establecer una remuneración equitativa para los autores por la reproducción de sus obras, entre otras razones por la dificultad de acreditar la condición de investigador de quien solicita la reproducción, teniendo en cuenta que uno de los requisitos es precisamente que el acto de reproducción se realice con fines de investigación.

Otra facultad patrimonial que se verá limitada es la de distribución, específicamente en lo relacionado con el préstamo. Se entenderá como préstamo la puesta a disposición del público de las obras en establecimientos accesibles a los usuarios, para que dichas creaciones se usen por un tiempo determinado, sin que se obtenga un beneficio económico por parte de la entidad que presta el servicio. Al igual que en el caso anterior, este límite ampara la actuación de bibliotecas públicas.

En cuanto a los requisitos que se requieren para la configuración válida de este límite a favor de bibliotecas públicas, es necesario que la obra haya sido divulgada previamente, teniendo en cuenta que si la obra se encontrase en el ámbito privado del autor se podrían afectar las facultades morales exclusivas que poseen los autores, particular este que coincide con el límite antes analizado ${ }^{10}$. En el caso del préstamo, a diferencia del límite antes analizado, no se hace necesario que se acredite un interés o finalidad determinada, pues el fundamento de este límite se encuentra en la difusión de la cultura, en virtud del derecho fundamental de acceso a la cultura, teniendo en cuenta que cualquier persona tiene derecho a acceder a la producción científica, literaria y cultural que existe en su país o en cualquier otro.

Dichos préstamos deben realizarse en establecimientos accesibles al público y sin que medie ánimo de lucro. Con respecto a la remuneración a los titulares de derechos, estos deben ser recompensados por los préstamos que se realicen de sus obras. El pago de la remuneración se efectuará a través de las entidades de gestión colectiva a la que pertenezcan los autores.

Se limita igualmente el derecho de comunicación pública en su modalidad de puesta a disposición al permitir la consulta mediante terminales especializados en determinados establecimientos.

Para que se configure este límite las obras afectadas deben formar parte de las colecciones del propio establecimiento, excluyéndose en consecuencia aquellas obras que hayan sido depositadas en esos establecimientos por otras razones. En todo caso se trata de consultas que no son masivas y que deben adecuarse al número de

10 Vid. Bercovitz Rodríguez Cano, R., Comentarios a la Ley de Propiedad Intelectual, 3ra ed., Ed. Tecnos, Madrid, 2007, pp. 731 y 732. 
ejemplares que posee la biblioteca, además de exigirse que la consulta se realice in situ, o sea, en la propia sala del establecimiento ${ }^{11}$.

Es pertinente apuntar que este límite se configura cuando la finalidad sea investigativa o encaminada a realizar estudios personales. Se requiere así mismo que la obra sea puesta a disposición de personas concretas del público, y no al público en general, entendiendo en consecuencia que en esa colectividad estarán comprendidas aquellas personas que soliciten el acceso a la obra en las bibliotecas públicas.

Por último, cabe señalar que al igual que los límites antes analizados, el autor o titulares del derecho de autor deben recibir una compensación por esta utilización, que en definitiva incide directamente sobre su derecho exclusivo. Dicha remuneración o compensación no tiene que ser necesariamente monetaria, sino que los autores pueden ser retribuidos o compensados de diversas maneras, como pudiera ser la ampliación de la difusión de su obra o incluso llevar a cabo proyectos culturales en los que se incluyan sus creaciones y de ese modo fomentar su puesta a disposición del público, garantizando que los usuarios puedan tener acceso a la cultura en general y contribuyendo a elevar el prestigio de los creadores, especialmente los noveles. Esta remuneración o compensación en todo caso debe ser tramitada por la entidad de gestión a la que el autor pertenezca.

Resulta atinado señalar que se configuraría este límite en aquellos supuestos en los que la consulta se efectúe por la red cerrada e interna, lo cual descarta la posibilidad de las consultas que se efectúen fuera de la instalación. Si ello no sucediera así, se estaría extralimitando dicho límite y contradiciendo a su vez la regla de los tres pasos, específicamente en lo relativo a no atentar contra la normal explotación de la obra.

Los límites al derecho de autor constituyen un tema controvertido. Sin embargo, la realidad indica que estos límites se erigen como puente entre los creadores y el público que disfrutará o se beneficiará del producto cultural. Estos no solo permiten que el público se beneficie, sino que de igual forma sirven a los creadores como fuente generadora de nuevos conocimientos, haciendo posible que el derecho de autor logre su finalidad: estimular la creación intelectual, proteger la difusión del conocimiento y la promoción de la creación, cuestiones que versan en la consagración del derecho de acceso a la cultura, del cual son garantes las bibliotecas públicas.

\section{PRESUPUESTOS TEÓRICOS-JURÍDICOS QUE \\ DEBEN AMPARAR LA PROTECCIÓN EN CUBA DE OBRAS \\ HUÉRFANAS PARA SU USO POR BIBLIOTECAS PÚBLICAS}

Como ha quedado expuesto, el uso de cualquier obra protegida por el derecho de autor, incluidas las huérfanas, no es arbitrario. Las propias normas autorales esta- 
blecen límites que amparan el uso de obras en dominio privado por terceros, como las bibliotecas públicas, con la finalidad de buscar una armonía entre facultades autorales o derechos subjetivos de los autores y los derechos fundamentales de la sociedad, tales como el acceso a la cultura, el conocimiento, la educación, entre otros.

El profesor Garbajo Gascón, tomando por base la norma constitucional española, considera que los límites al derecho exclusivo encuentran su principal justificación en la propia estructura democrático-social del derecho de propiedad: la función social de la propiedad reconocida constitucionalmente, en relación con la promoción por el legislador de derechos fundamentales y principios rectores de la política económica y social, como la libertad de expresión, de creación, de comunicación y de información o la promoción, defensa y acceso a la cultura, la ciencia y la investigación ${ }^{12}$.

Con base en criterios constitucionales de la corte colombiana en cuanto a los derechos de autor, Pabón Cadavid sintetiza las razones que en su opinión justifican la existencia de estas excepciones. Argumentos que se traen a colación por considerar que acertadamente ponen al descubierto el fundamento que de los límites al derecho exclusivo de los autores. De tal modo el autor en cuestión expone, como razones en las cuales se fundamenta el interés estatal para establecer limitaciones, las siguientes ${ }^{13}$ :

- Función social de la propiedad (excepción de uso privado en el ámbito doméstico).

- Proteger la educación (excepción de comunicación pública para fines de enseñanza).

- Buscar la difusión de la cultura (excepción de reproducción para enseñanza).

- Lograr la eficacia de la ley (excepción para organismos de radiodifusión).

- Lograr mayor participación ciudadana en la vida democrática (reproducción de leyes).

- Buscar que los derechos de autor no sean un obstáculo para las nuevas creaciones (derecho de cita).

- No obstaculizar actividades ni investigaciones judiciales (reproducción para actuaciones judiciales).

- Conservar y proteger el patrimonio cultural (excepción para bibliotecas).

Teniendo en cuenta el uso que hacen las bibliotecas públicas de las obras huérfanas, resulta oportuno el establecimiento de presupuestos teórico-jurídicos que

12 Vid. Garbajo Gascón, F., Reproducción y préstamo público en bibliotecas y otras instituciones de promoción cultural. Su adaptación al entorno digital. Actas de Derecho Industrial y Derecho De Autor, t. xxıv, Ed. Instituto de Derecho Industrial de la Universidad de Santiago de Compostela, 2004, pp. 160 y 161.

13 Cfr. Pabón Cadavid, J., Guía de Derecho de Autor para Bibliotecas, isbn: 978-958-716446-6, 2011, p. 31. Disponible en https://www.researchgate.net/publication/265856671_Guia_de_Derecho_de_Autor_para_Bibliotecas. Consultado el 26 de octubre 2018. 
coadyuven a su uso por estas instituciones, sin que ello implique vulnerar los derechos de sus autores.

\section{A. PRIMER PRESUPUESTO TEÓRICO-JURÍDICO: REGULACIÓN JURÍDICA DE LA OBRA HUÉRFANA A PARTIR DEL RECONOCIMIENTO DE LOS REQUISITOS DE ORFANDAD}

Las obras huérfanas son generalmente conocidas como todas aquellas que están protegidas por la propiedad intelectual pero cuyo titular de derechos no puede ser localizado o identificado, lo cual imposibilita la obtención de una autorización previa para usar dichas obras ${ }^{14}$. Aquellas están compuestas por dos elementos. Por un lado, se aplica en aquellos casos en los que el titular de derechos no es localizable, y también se aplica cuando existen problemas en relación con la identificación de este.

La falta de identificación o localización del autor o titular de dicha obra genera un problema, ya que en el caso de que un tercero desee usar esta creación le va a resultar prácticamente imposible obtener la autorización expresa del autor de dicha obra. Ello podría generar la imposibilidad de acceso al acervo cultural que poseen esas creaciones y de las cuales el público consumidor quiere hacer uso, salvo que una regulación legal disponga que se puede realizar su uso aun cuando se encuentra en esas condiciones.

Las regulaciones sobre las obras huérfanas plantea un desafío. Toda legislación que permita el uso de las obras sin obtener la autorización previa del autor o titular de derechos está estableciendo una restricción sobre el ejercicio de las facultades reconocidas por ley a los autores sobre sus creaciones, al propio tiempo que podría constituirse una violación de las facultades autorales, teniendo en cuenta que la obra se encuentra, en la mayoría de los casos, en el dominio privado del autor, lo cual implica que ostente todas las facultades autorales sobre su creación.

Debido a la falta de regulación sobre las obras huérfanas, estas pueden ser finalmente excluidas del mercado, limitando de ese modo que los usuarios puedan hacer uso de ellas. Esta incertidumbre es la que justifica la existencia de su regulación jurídica, con el objetivo de asegurar el acceso a dichas creaciones. De esta forma, se genera el desafío de establecer un mecanismo legal adecuado para permitir el uso de dichas obras.

A pesar de su relevancia, la ley cubana de derecho de autor no se pronuncia sobre las obras huérfanas. De tal modo, no es posible usar este tipo de obras en la medida que no se cuenta con la autorización expresa del autor o titular de derechos, salvo que el acto que se quiera realizar pueda ser vinculado con alguna de

14 Vid. Walker Echenique, E., Uso de obras huérfanas: estudio de diversas regulaciones en el Derecho Comparado como referencia para modernizar la regulación chilena sobre propiedad intelectual. Revista Chilena de Derecho, vol. 41, n. ${ }^{\circ} 3$, Ed. Goldenberg Serrano, Juan Luis, 2014, p. 846. 
las excepciones legales que determina la Ley 14/1977, específicamente el límite a favor de bibliotecas, incluidas las públicas.

Hasta el momento no existe en la legislación cubana normativa alguna relativa a las obras huérfanas; sin embargo, el Centro Regional para el Fomento del Libro en América Latina y el Caribe (Cerlalc) ${ }^{15}$ ha recomendado el respeto al derecho de autor de esas obras, el despliegue de una búsqueda diligente de los autores o titulares del derecho, la posibilidad de permitir el uso de esas obras a las bibliotecas y su digitalización a través de licencias que subsidiariamente pudieran otorgar entidades de gestión colectiva, siempre que esas instituciones se consideren estrictamente necesarias para el cumplimiento de las funciones de las bibliotecas y sin fines lucrativos, previéndose la posibilidad de que el autor pueda controlar su obra en cualquier momento, una vez identificado o localizado.

Sin embargo, cabe señalar que a pesar de que las obras huérfanas no tienen una mención específica en la ley cubana de derecho de autor, se extiende hacia ellas la protección general que esta ley brinda a los creadores de obras. Por ello vale la pena la adopción de disposiciones normativas que regulen de manera específica el alcance que se puede hacer de estas creaciones que se encuentran en estado de orfandad.

Para dicha regulación pudiera ser tomada como referencia la Directiva del Parlamento Europeo y del Consejo sobre ciertos usos autorizados de las obras huérfanas, dictada el 25 de octubre del 2012. Dicha directiva constituye una de las pocas regulaciones que existen sobre el uso o explotación de las obras huérfanas y se caracteriza por establecer un régimen de excepciones legales que permitirán el uso de este tipo de obra sin requerir la autorización previa del titular o de alguna entidad facultada para otorgarla.

La directiva pretende regular el uso de las obras huérfanas para eliminar obstáculos que impidan u obstruyan el acceso a la información y consecuentemente el desarrollo de la innovación ${ }^{16}$. Al propio tiempo indica que el derecho de autor constituye el fundamento económico de la industria o sector creativo, estimulando la innovación, creación, producción e inversión ${ }^{17}$. De tal manera, es posible afirmar que, bajo la lógica de la directiva, la regulación sobre uso de obras huérfanas no se opone a los fundamentos de la propiedad intelectual, sino que los complementa.

La norma que establezca la regulación jurídica de las obras huérfanas debe partir de reconocer los requisitos que desde la doctrina se han admitido para clasificar este tipo de obras. En tal sentido habrá que reconocer, en primer lugar, que son obras sujetas al período de protección del derecho de autor; en segundo

15 Cfr. Al respecto Circular n. 2 del Centro Regional para el Fomento del Libro en América Latina y el Caribe para las bibliotecas públicas y privadas de Latinoamérica y el Caribe, de 16 de marzo de 2012. Disponible en https://www.propiedadintelectual.gob.cl/623/ w3-article-10432.html?_noredirect=1. Consultado el 27 de enero de 2019.

16 Cfr. Considerando 2, Directiva 2012/28/EU del Parlamento Europeo y del Consejo sobre ciertos usos autorizados de las obras huérfanas.

17 Cfr. Considerando 5, Directiva 2012/28/EU del Parlamento Europeo y del Consejo sobre ciertos usos autorizados de las obras huérfanas. 
lugar, que sus autores no pueden ser identificados o se encuentran ilocalizables, a pesar de haber efectuado una búsqueda diligente, siendo este el tercer requisito, $y$, por último, en cuarto lugar, que exista una persona que pretenda realizar actos de explotación de dichas creaciones.

\section{B. SEGUNDO PRESUPUESTO TEÓRICO-JURÍDICO:}

ESTABLECIMIENTO DE UN SISTEMA DE LÍMITES A FAVOR DE LAS BIBLIOTECAS PÚBLICAS QUE AMPAREN EL USO DE OBRAS HUÉRFANAS

La problemática de las obras huérfanas nace de los proyectos de digitalización y comunicación en línea a gran escala que llevan a cabo las bibliotecas, teniendo en cuenta que se trata de obras cuyos autores no pueden ser identificados o localizados, y en consecuencia no se podía conseguir la autorización preceptiva para su utilización. Por todo ello instituciones como las bibliotecas públicas deberían ser dispensadas de obtener el consentimiento de los titulares del derecho de autor de este tipo de obras para llevar a cabo actos que no entran en conflicto con los intereses económicos de los autores y titulares, siempre y cuando dichas instituciones no persigan fines lucrativos.

Se considera que no existe ningún obstáculo jurídico que impida una ampliación del límite a favor de bibliotecas. Dicha ampliación consistiría en describir, en función de la finalidad perseguida, los actos que estas instituciones podrían llevar a cabo sin contar con el previo consentimiento de los titulares de derechos de obras huérfanas, en aras de posibilitar que dichas obras puedan ser utilizadas por estas instituciones sin que ello constituya una violación al derecho de autor.

Valdría la pena tomar como referencia a España, país que con avanzada técnica ha establecido en su Texto Refundido de la Ley de Propiedad Intelectual lo relativo a las obras huérfanas en su artículo 37 bis. En dicho precepto se prevé la posibilidad de que las obras huérfanas sean reproducidas a efectos de digitalización, puestas a disposición del público, indexación, catalogación, conservación o restauración, previéndose de este modo una forma específica de comunicación pública según prevé el artículo 20 apartado 2 del propio cuerpo legal.

El límite a favor de bibliotecas debiera permitir que estas instituciones realicen actos de reproducción, comunicación pública, transformación e incluso la distribución de las obras reproducidas, teniendo en cuenta que se trata de facultades patrimoniales que pueden ser transmitidas a terceros o incluso quedar amparadas dentro de los límites admitidos al derecho de autor que se encuentran establecidos en la ley. No obstante, de no existir el límite estas actividades se realizarían sin autorización del creador de la obra, configurándose violaciones al derecho de autor.

De igual modo, los actos de utilización de obras huérfanas que lleven a cabo las bibliotecas públicas deberán realizarse con respecto a obras ya divulgadas, sin ánimo de lucro y con el fin de alcanzar objetivos relacionados con su misión de interés público y facilitadoras del acceso a la cultura, con fines culturales y educativos. 
En consecuencia, se podrá permitir que las obras huérfanas que forman parte del acervo de las bibliotecas públicas sean reproducidas o consultadas mediante una red, que pudiera ser en todo caso la intranet, o que puedan ser objeto de préstamo a terceras personas o interbibliotecario. En todos los casos supone una injerencia a las facultades patrimoniales reconocidas a los titulares del derecho de autor, que se justifica en aras de lograr el adecuado equilibrio entre los intereses de los creadores y el interés general de la sociedad, en particular el acceso a la cultura y el fomento de la investigación ${ }^{18}$.

Naturalmente, no se debe perder de vista los intereses de autores y titulares de derecho. No se trata de permitir que las bibliotecas públicas pongan a disposición de los usuarios las obras huérfanas de manera tal que se perjudique de forma irrazonable los intereses legítimos de autores y titulares de derecho, sino que es necesario tener en cuenta la regla de los tres pasos, en virtud de la cual dicho límite a favor de bibliotecas públicas, ahora ampliado para amparar el uso de obras huérfanas, no debe atentar contra la normal explotación de la obra protegida por el derecho de autor ni causar un perjuicio injustificado a los legítimos intereses de los titulares de derechos.

\section{TERCER PRESUPUESTO TEÓRICO-JURÍDICO:}

ADECUACIÓN DEL SISTEMA DE LÍMITES A FAVOR DE LAS

BIBLIOTECAS PÚBLICAS A LA REGLA DE LOS TRES PASOS

Como es sabido, la regla de los tres pasos constituye un referente indispensable en materia de límites al derecho de autor. Con su aplicación se logra que el límite establecido a los derechos exclusivos de los autores cumpla con una serie de requisitos que posibilitan su puesta en práctica.

Como se ha dicho, es aceptado que todo el sistema de límites a favor de bibliotecas públicas se considera un "determinado caso especial". Al analizar este primer criterio de la regla, el término "determinados" significa que el límite a favor de bibliotecas previsto en la legislación nacional debe estar claramente definido. En este sentido, existe la necesidad de una exacta definición del contenido de dicho límite, mediante la identificación de los actos limitados, las obras afectadas, los equipos utilizados y sus potenciales beneficiarios, entre otros factores.

No obstante, no sería necesario identificar explícitamente todas y cada una de las situaciones posibles a las que podría aplicarse el límite. Bastaría que el alcance del sistema de límites a favor de bibliotecas públicas fuera conocido y particularizado a fin de garantizar un grado suficiente de seguridad jurídica. Lo que se requiere, por tanto, es una tipificación legal del límite, de manera que este se encuentre definido

18 Vid. Carrancho Herrero, M. T., "Reproducción, préstamo y consulta en museos, archivos, bibliotecas y otras instituciones”, en De Román Pérez, R. (coord.), Propiedad Intelectual en las universidades públicas, ob. cit., p. 144. 
de modo preciso, evitando descripciones genéricas y de poca densidad semántica, que pudiesen amenazar la seguridad jurídica.

Igualmente, además de determinables, los casos objeto de limitación deben ser "especiales", de forma que una definición clara del sistema de límites a favor de bibliotecas públicas no sería, per se, suficiente para dar cumplimiento al primer requisito de la regla. Más allá de esto, el límite a favor de bibliotecas públicas debe ser excepcional en su alcance, tanto en sentido cualitativo como cuantitativo. Esto significa, en otras palabras, que dicho límite debe ser aplicado solamente en situaciones específicas y restrictas, beneficiando a un número reducido de usuarios.

El segundo criterio de la regla de los tres pasos referido a la prohibición de que dicho límite atente contra la explotación normal de la obra puede ser considerado el de más difícil interpretación, y se constituye en la barrera principal de la regla. Este segundo paso resulta un parámetro exclusivamente económico teniendo en cuenta que todo el sistema de límites que se establezca a favor de bibliotecas públicas no debe atentar contra la normal explotación de la obra.

En correspondencia con ello, resulta necesario hacer referencia al alcance del término "explotación", a pesar de que este no ofrezca grandes desafíos y aluda a la actividad mediante la cual los titulares del derecho de autor utilizan los derechos exclusivos que les han sido conferidos para obtener un valor económico de sus derechos sobre esas obras. Así, de acuerdo con ello, si un límite impide que el titular del derecho obtenga un rendimiento económico de la explotación de la obra en el mercado, dicho límite, en principio, sería contrario al segundo paso de la regla.

Cabe verificar en este supuesto si el sistema de límites a favor de bibliotecas públicas va en detrimento de dicha explotación, porque solamente en dicho caso el límite en cuestión será contrario al segundo paso de la regla. Para que este límite atente contra la explotación normal de una obra debe existir, por parte del titular del derecho, además de una expectativa razonable de obtención de un beneficio económico relevante, una afectación sustancial del potencial de la obra.

El tercer paso de la regla podría ser considerado el más importante. Este paso admite como justificación para afectar los intereses legítimos del autor la protección de derechos fundamentales e intereses colectivos, como el acceso a la cultura. Para que un interés del autor o titular de derechos sea legítimo se hace necesaria la ponderación de dichos intereses (de los autores o titulares) con otros intereses de terceros que sirven de fundamento para la existencia de un determinado límite. Sería el caso del límite a favor de bibliotecas públicas, donde se pretende conciliar el derecho de autor con intereses sociales como la cultura, la educación y la información, respondiendo de este modo a un interés social, el acceso a la cultura.

La cuestión fundamental de este tercer paso de la regla consiste en analizar el grado o nivel del perjuicio que podría considerarse injustificado, es decir, la proporcionalidad entre el sacrificio del autor o titular de derechos y las ventajas que obtienen los beneficiarios del límite. De ese modo, la alocución "perjuicio 
injustificado" permite modular la aplicación de la regla en función de los intereses que fundamentan el límite en cuestión.

Así, también el tercer criterio de la regla de los tres pasos exige el análisis del objetivo que subyace al límite para calificar el perjuicio y, en consecuencia, admitir o rechazar un límite del sistema. Es decir, el titular del derecho no debe tener el poder de controlar todas las utilizaciones de sus obras que le perjudiquen, pues algunos perjuicios están justificados por valores que se estiman superiores a sus intereses. Lo que busca el tercer criterio de la regla es ofrecer una garantía a todas las partes -autores y usuarios- de manera que se alcance un equilibrio entre los mismos mediante un juicio de ponderación entre sus respectivos intereses. La incorporación de la regla de los tres pasos al derecho interno de cada país ha llevado a una ampliación subjetiva de sus destinatarios, pasando esta a ser aplicada por los jueces y tribunales como norma de interpretación de los límites existentes en cada legislación interna.

Para enfrentar la nueva situación que está teniendo lugar, o sea, la aparición del entorno digital, se han previsto tres formas diferentes de solución: legislativa, tecnológica y contractual. La primera consiste en modificar las leyes adoptándolas a la nueva realidad, la segunda solución se refiere a sistemas que identifican las obras y controlan su uso, mientras que la vía contractual alude a la posibilidad de que las obras puedan ser utilizadas de acuerdo con lo establecido en las licencias exclusivas, mediante contratos entre el autor de la obra y terceras personas ${ }^{19}$.

Las leyes de derecho de autor intentan establecer un equilibrio entre los intereses de los autores, los que explotan comercialmente sus obras y los usuarios, razón que justifica el establecimiento de límites a los derechos de autor. El equilibrio tradicional resuelto por los límites está siendo puesto en peligro debido a la utilización de las vías tecnológica y contractual. Dicha amenaza se encuentra en que a través de tales soluciones queden invalidados los límites, especialmente el reconocido a favor de bibliotecas públicas, teniendo en cuenta que en el caso de los contratos los términos y condiciones establecidos en el mismo podrían anular los límites al derecho de autor, así como las medidas tecnológicas provocarían de igual modo un ineficacia de los límites, teniendo en cuenta que los titulares de derechos han establecido mecanismos para controlar el uso que se realiza de sus creaciones.

\section{CONCLUSIONES}

Una obra es huérfana cuando sus autores no pueden ser identificados o localizados por quienes pretenden realizar actos de utilización y comercialización de las obras, a pesar de haberse efectuado una búsqueda diligente de dichos autores. Sin embargo, son obras protegidas por el derecho de autor, y sus creadores ostentan el derecho

19 Vid. Fernández Molina, J. C., Protección tecnológica y contractual de las obras con derecho de autor: ¿Hacia una privatización del acceso a la información?, Ciência da Informaçâo (serie en internet), vol. 32, n. ${ }^{\circ}$ 2, 2003, pp. 54-55 Disponible en http://www.scielo.br/pdf/ci/ v32n2/17033.pdf. Consultado el 24 de marzo de 2019. 
subjetivo que les otorga un conjunto de facultades morales y patrimoniales sobre estas creaciones expresadas formalmente que se distinguen por su originalidad. Cualquier acto de explotación de la obra debe contar con la correspondiente autorización del autor o estar amparado por un límite que justifique su utilización.

Obras de este tipo pueden ser utilizadas por bibliotecas públicas al amparo de un sistema de límites que legitimen su actuación. Estas instituciones pueden realizar reproducciones, préstamos y consultas en terminales especializados de obras huérfanas, siempre que sea con fines de investigación, sin ánimo de lucro y en aras de salvaguardar un interés público como el derecho de acceso a la cultura.

En aras de garantizar un justo equilibrio entre los autores de las obras huérfanas, el público que pretende acceder a estas creaciones y las bibliotecas públicas, resulta necesario el establecimiento de presupuestos teórico-jurídicos que amparen el uso de este tipo de obras por las bibliotecas públicas. Estos presupuestos deben partir del reconocimiento legal de las obras huérfanas, estableciendo los requisitos de orfandad, y en correspondencia con ello ampliar el límite a favor de bibliotecas públicas, con apoyo en la regla de los tres pasos. Todo ello debe tener lugar, teniendo en cuenta que en la ley autoral cubana existe un reconocimiento expreso del límite a favor de bibliotecas; sin embargo, no se incluye en este el uso que pueden realizar dichas instituciones de las obras huérfanas.

La regulación jurídica de las obras huérfanas en la Ley Derecho de Autor cubana garantizará la circulación de dichas creaciones en beneficio del interés público. En consecuencia, las bibliotecas públicas, amparadas en un sistema de límites que no atente contra la normal explotación de la obra ni cause un perjuicio injustificado a los legítimos intereses de los autores de dichas obras, podrán hacer uso de esas creaciones, siempre que se garantice el equilibrio que debe existir entre la actividad de las bibliotecas públicas y los derechos de autor, y se eliminen situaciones de conflicto.

\section{REFERENCIAS}

\section{DOCTRINA}

Alonso Arévalo, J., Garbajo Gascón, F., y Cordón García, J. A., "La propiedad intelectual y los derechos de autor en bibliotecas y centros de información: revistas digitales y acceso abierto", en Torres RipA, J., y Gómez HernándeZ, J. A. (coords.), El copyright en cuestión: diálogo sobre propiedad intelectual, Bilbao, Deusto, 2011, pp. 143-168. Disponible en http://hdl.handle. net/10760/18064, consultado el 8 de octubre de 2019.

Antequera Parilli, R., derecho de autor, tomo I, Servicio Autónomo de la Propiedad Intelectual, Dirección Nacional de derecho de autor, Caracas, 1998.

Antequera Parilli, R., Estudios de derecho de autor y Derechos afines, Ed. Reus, Madrid, 2007. 
Antequera Parilli, R., "Los límites del derecho Subjetivo y del derecho de autor", en RogelVide, C. (coord.), Los límites del derecho de autor, Ed. Reus, Madrid, 2006.Bercovitz Rodríguez Cano, R., Comentarios a la Ley de Propiedad Intelectual, 3ra ed., Ed. Tecnos, Madrid, 2007.

Carrancho Herrero, M. T., "El concepto de obra de plástica y la impresión en 3D”, en Espín Alba, I. (coord.), Propiedad intelectual en el siglo xxi: nuevos continentes y su incidencia en el derecho de autor, Ed. Reus, Madrid, 2014.

Carrancho Herrero, M. T., "Reproducción, préstamo y consulta en museos, archivos, bibliotecas y otras instituciones", en De Román Pérez, R. (coord.), Propiedad Intelectual en las universidades públicas. Titularidad, gestión y transferencia, Ed. Comares, Granada, España, 2016.

Fernández Molina, J. C., Protección tecnológica y contractual de las obras con derecho de autor: ¿Hacia una privatización del acceso a la información?, Ciência da Informaçâo (serie en internet), vol. 32, n. ${ }^{\circ}$ 2, 2003, pp. 54-55 Disponible en http://www.scielo.br/pdf/ci/v32n2/17033.pdf. Consultado el 24 de marzo de 2019

Garbajo Gascón, F., Reproducción y préstamo público en bibliotecas y otras instituciones de promoción cultural. Su adaptación al entorno digital. Actas de Derecho Industrial y Derecho de Autor, t. xxiv, Ed. Instituto de Derecho Industrial de la Universidad de Santiago de Compostela, 2004, pp. 160 y 161.

Lipszyc, D., Derecho de autor y derechos conexos, Ed. Félix Varela, La Habana, 2005 , t. I.

Navarro Costa, R., "Algunas cuestiones sobre propiedad intelectual, bibliotecas e internet", en Cuena Casas, M., Anguita Villanueva, L.A. y Ortega Doménech, J. (coord.), Estudios de Derecho Civil en homenaje al profesor Joaquín José Rams Albesa, Ed. Dykinson, Madrid, 2013.

Palau Ramírez, F. y Palao Moreno, G., Comentarios a la Ley de Propiedad Intelectual, Ed. Tirant lo Blanch, Valencia, 2017.

Pabón Cadavid, J., Guía de Derecho de Autor para Bibliotecas, isbn: 978-958716-446-6, 2011, p. 31. Disponible en https://www.researchgate.net/publication/265856671_Guia_de_Derecho_de_Autor_para_Bibliotecas. Consultado el 26 de octubre 2018. Riera Barsallo, P., Los Derechos de Autor y sus límites: un equilibrio necesario, p. 2. Disponible en http://openaccess.uoc.edu/webapps/ o2/bitstream/10609/304/1/3527.pdf. Consultado el 23 de enero de 2019.

RogelVide, C., derecho de autor, Ed. Cálamo, Madrid, 2004.

RogelVide, C. (coord.), Los límites del derecho de autor, Ed. Reus, Madrid, 2006. RogelVide, C. y Serrano Gómez, E., Manual de derecho de autor, Ed. Reus, Madrid, España, 2008.

Rodríguez Moreno, S., La nueva normativa italiana en materia de obras huérfanas, Revista La Propiedad Inmaterial, ${ }^{\circ} 20$, Universidad Externado de Colombia, julio-diciembre de 2015, pp. 135-151. Disponible en https://ssrn.com/ abstract=2719068. Consultado el 10 de abril de 2020 . 
Serrano Fernández, M. (coord.), Estudio de los límites a los derechos de autor desde una perspectiva de derecho comparado. Reproducción, préstamo y comunicación pública en bibliotecas, museos, archivos y otras instituciones culturales, Ed. Reus, Madrid, 2017.

Serrano Fernández, M., "Los derechos de explotación de las obras huérfanas en el entorno digital: las dificultades de transposición de la Directiva 2012/28UE al ordenamiento jurídico español", en Serrano Gómez, E. (director), Anuario de Propiedad Intelectual 2013, Ed. Reus, Madrid, 2014.

Serrano Gómez, E. (coord.), Obras inéditas, anónimas, seudónimas, póstumas y huérfanas, Ed. Reus, Madrid, 2014.

Traviño, G., De los límites al derecho de autor y las posibilidades de su ejercicio, Revista Themis 36, p. 192. Disponible en https://dialnet.unirioja.es/descarga/ articulo/5109708.pdf. Consultado el 13 de diciembre de 2018.

VALDÉs DíAz, C., "Los límites al derecho de autor a favor de bibliotecas en los países latinoamericanos. Especial referencia a Cuba", en Serrano Fernández, M. (coord.), Estudio de los límites a los derechos de autor desde una perspectiva de derecho comparado. Reproducción, préstamo y comunicación pública en bibliotecas, museos, archivos y otras instituciones culturales, Ed. Reus, Madrid, 2017.

Valdés Díaz, C. C., Derecho de autor y derechos conexos, Ed. Félix Varela, La Habana, 2016.

Walker EChenique, E., Uso de obras huérfanas: estudio de diversas regulaciones en el Derecho Comparado como referencia para modernizar la regulación chilena sobre propiedad intelectual. Revista Chilena de Derecho, vol. 41, n. ${ }^{\circ} 3$, Ed. Goldenberg Serrano, Juan Luis, 2014, p. 846.

TEXTOS LEGALES

Circular n. ${ }^{\circ} 2$ del Centro Regional para el Fomento del Libro en América Latina y el Caribe para las bibliotecas públicas y privadas de Latinoamérica y el Caribe, del 16 de marzo de 2012. Disponible en https://www.propiedadintelectual. gob.cl/623/w3-article-10432.html?_noredirect=1. Consultado el 27 de enero de 2019.

Convenio de Berna para la Protección de Obras Literarias y artísticas. Publicaciones OMPI, n. ${ }^{\circ} 223(\mathrm{~s})$, Ginebra, 1999, ISBN 92-805-0649-8. Disponible en https://www.wipo.int/treaties/es/text.jsp?file_id=283698. Consultado el 25 de septiembre de 2018.

Decreto Ley n. 271 "De las bibliotecas de la República de Cuba". Gaceta oficial. Edición ordinaria. 030, 10 de agosto de 2010, pp. 873-877. Disponible en http://www.gacetaoficial.cu, consultado el 29 de noviembre de 2018.

Directiva 2001/29/CE del Parlamento Europeo y del Consejo del 22 de mayo de 2001 relativa a la armonización de determinados aspectos de los derechos de 
autor y derechos afines a los derechos de autor en la sociedad de la información. Disponible en https://eur-lex.europa.eu/LexUriServ/LexUriServ.do?uri=CELE x:32001L0029:Es:HTML. Consultado el 25 de enero de 2019.

Directiva 2012/28/UE, del Parlamento Europeo y del Consejo, del 25 de octubre de 2012, sobre ciertos usos autorizados de las obras huérfanas. Disponible en https:/eur-lex.europa.eu/legal-content/ES/TXT/PDF/?uri=CELEX:32012L0028 \&from=en. Consultado el 9 noviembre de 2018.

Ley sobre Derecho de autor cubana, Ley 14 de 28 de diciembre de 1977. Gaceta Oficial, Edición Ordinaria, La Habana. Disponible en http://www.gacetaoficial. cu, consultado el 25 de septiembre de 2018 .

Real Decreto Legislativo 1/1996, de 12 de abril, que aprueba el Texto Refundido de la Ley de Propiedad Intelectual española: Boe-A-1996-8930. En Ortega Doménech, J., y Anguita Villanueva, L. A., Ley de Propiedad Intelectual, actualizada a junio de 2018, Ed. Reus, 2da edición, Madrid, 2018. 